Research Article

\title{
The Measures of Efficiency of Power Generation Plants in Sylhet of Bangladesh
}

\author{
Kanis Fatama Ferdushi, ${ }^{1}$ Anton Abdulbasah Kamil ${ }^{(D)},{ }^{2}$ Saleh Ahmed, ${ }^{1}$ \\ and Luthful Alahi Kawsar' \\ ${ }^{1}$ Department of Statistics, Shahjalal University of Science and Technology, Sylhet 3114, Bangladesh \\ ${ }^{2}$ Faculty of Economics, Administrative and Social Sciences, Istanbul Gelisim University, Istanbul, Turkey \\ Correspondence should be addressed to Anton Abdulbasah Kamil; akamil@gelisim.edu.tr
}

Received 4 December 2019; Revised 2 March 2020; Accepted 30 March 2020; Published 1 May 2020

Academic Editor: Niansheng Tang

Copyright (c) 2020 Kanis Fatama Ferdushi et al. This is an open access article distributed under the Creative Commons Attribution License, which permits unrestricted use, distribution, and reproduction in any medium, provided the original work is properly cited.

\begin{abstract}
This study measures the performance of power generation plants in Sylhet region of Bangladesh considering twenty-four-month monthly dataset during 2013-14. To measure the performance of those plants, gross electricity generation was considered as output for the stochastic frontier model, whereas fuel consumption, lube oil consumption, auxiliary consumption, cost, heat rate, and hours of run were considered as input variables. Based on the log-likelihood hypothesis test, trans-log production model is preferred over Cobb-Douglas (C-D) production model for this study. The average efficiency of the selected plants is above 90 percent, and there is Sylhet Combined Cycle Power Plant (CCPP) which has an efficiency of about 78.6 percent for truncated normal distribution. In the time-variant inefficiency effects model, fuel consumption, cost, square product of lube oil consumption, interaction between fuel consumption and lube oil consumption as well as auxiliary consumption, and hours of run have a significant positive influence on power generation. On the other hand, some input variables such as hours of run and interaction between cost and heat rate have a significant negative influence on power generation. The estimated values of the timevarying inefficiency parameter $\eta$ are positive for both the truncated and the half-normal distribution. This result indicates that technical efficiency has declined over the reference period of the study.
\end{abstract}

\section{Introduction}

Electricity is the main source of power of a country, and most of the economic activities depend on this power. Bangladesh is the most densely populated country in the world and also considered one of the most arousing energy growth nations. The rapid increase of economic and population growth has resulted in increasing electricity demand in Bangladesh [1,2]. Although the number of power plants is increased from 108 to 127, the demand for electricity could not be mitigated. Moreover, the nation's power generation units have repeatedly become unable to meet system demand over the past decade $[2,3]$. Power generation has been accelerated through different resources (solar, renewable energy, etc.) in Bangladesh, but mass people could never enjoy hundred percent electrification, and people are still facing the problem of load shedding in urban and rural areas.

There are many areas in Bangladesh where electricity facilities do not exist properly even in this twentieth century. In other words, more than a third of Bangladesh's 166 million people still deprive from access to electricity, while the country hardly can produce some of its 11,500 megawatts (MW). The installed capacity of power generation in Bangladesh was $1,437 \mathrm{MW}$ in 1986 . More than $90 \%$ of the nation's power was generated by steam turbine, gas turbine, or combined cycle power stations using domestically available natural gas. The total installed capacity is 20,000 MW (combining solar power) as of September 2018. The government of Bangladesh (GoB) has declared and aimed to provide electricity for the people living in Bangladesh by the year 2021 [4]. According to the Power System 
Master Plan, the government of Bangladesh has planned to generate 11,450 MW power from domestic coal and $8,400 \mathrm{MW}$ from import coal within 2030 [4]. Despite the fact that there is showed many initiative, however another significant obstacle is facing to deliver generated power efficiency. It has been estimated that one-third of the total generation are losses due to transmission and distribution. In this case, we have to pay serious attention to combat various difficulties in the energy sector whereas the Bangladesh Government is interested to undertake various projects to accommodate new policies. The rapidly growing demand also can be mitigated by considering and implementing the new innovative project in both residential and industrial sectors. The advantage of energy resources may play a vital role in economic development of sustainable infrastructure development and finally can save insecurity in any country. The performance or efficiency measure in the power generation plants has not yet taken place in Bangladesh. The energy efficiency of high energy-consuming industries plays a contributing role in social sustainability, economic performance, and environmental protection of any nation [5]. Liu et al. [6] stated that power industry is the basis of economy and society developments.

The power sector in Bangladesh was less developed than that in other developing countries in Asia. Recently, Bangladesh started construction of the 2.4-gigawatt Rooppur Nuclear Power Plant expected to go into operation in 2023. According to the Bangladesh Power Development Board (BPDB) in July 2018, 90 percent of the population had access to electricity [7]. However, the per capita energy consumption in Bangladesh is considered low. Meanwhile, the load shedding distracts economic growth which makes economic activities slower. Fortunately, urban people are pursuing greater convenience and comfort in their daily lives for their location, but rural people are deprived from modern facilities even from their compulsory farming activities. The largest energy consumers in Bangladesh are industries and the residential sector, followed by the commercial and agricultural sectors. Agriculture is the main source of income for the rural people of the country, and there is a huge demand for electricity in dry season. Hassan et al. [8] showed that in generating and distributing electricity, the failure to adequately manage the load leads to extensive load shedding resulting in severe disruption in the industrial production and other economic activities. For this reason, many people in rural areas are migrating urban areas for work. As a result, the urban areas have become denser. The demand of electricity of capital increases more and more at a significantly high rate. This demand is driven by the continued growth in gross domestic production in recent years. Islam and Khan [9] showed that Bangladesh is producing more power generation with less energy compared to some higher-income countries. So Bangladesh has the potentiality to do better and achieve higher economic growth by supplying electricity properly. Geller et al. [10] showed the energy efficiency policies and programs adopted by California. Their experience shows that well-designed policies can save substantial energy. If it is possible to know the existing level of efficiency of electricity generation in
Bangladesh by using the techniques of efficiency, then limited resources cannot create hindrance. In that case, policy makers can be able to make a master plan to increase the production level up to the maximum level and savings as well.

A firm is efficient means this firm can produce the maximum level of output for a given level of input on the assumption that technology is fixed. Efficiency scores vary across producers, and they can be related to firm's characteristics such as size, ownership, and location. Thus, one can identify and remove sources of inefficiencies from the process using the allocated resources properly. The common characteristic of the technical efficiency estimation techniques is that information is extracted from optimum observations from a body of data to determine the best practice production frontier. The study of frontier begins with Farrell [11] who suggested that efficiency could be attained by using minimum level of input under certain production technology to produce maximum level of output. The stochastic frontier analysis (SFA) depends on the model with composed error terms; one kind of error is due to technical inefficiency parameters and others due to random shocks. The stochastic frontier analysis approach is based on the idea that an economic unit may operate below its production frontier level due to pure errors and some uncontrollable factors. Some researchers had used parametric method SFA and nonparametric method DEA to measure efficiency in energy sector and recommended policy maker to eliminate those difficulties. Lin and Long [12] adopted or applied the stochastic frontier analysis to study the average efficiency and energy-saving potentiality of the chemical industry. Mardani et al. [13] showed data envelopment analysis (DEA) is a good evaluative model which is a nonparametric efficiency measuring tool for efficiency measurement. Otsuka [14] used SFA to estimate the energy demand function and analyze the levels and determinants of energy efficiency. Another prominent researcher, Sueyoshi et al. [15], examined a recent research trend on DEA applications from 1980s to 2010 s on his meta-analysis.

\section{Materials}

The main input parameters that need to consider when calculating the efficiency of a power plant are fuel calorific value, steam tonnage, enthalpy change during expansion in turbine, auxiliary consumptions of equipment, and efficiency of major equipment such as turbines, generator, and pumps. According to operational perspective, the efficiency we calculated for this work is mainly combined cycle power plant. A combined cycle power plant is operated by a gas turbine as a topping cycle which is a ranking cycle where exhaust heat of sufficiently high temperature is drawn to the heat recovery steam generator. Heat recovery steam generator produces superheated steam which drives a steam turbine. So basically it is a waste heat recovery plant which yields higher efficiency than a conventional gas turbine or steam turbine plant. So for calculating the efficiency, we only take the fuel input for gas turbine and heat content for combustion as an input. The output is taken from both the 
generators for gas turbine and steam turbine. Different instruments are pointed on different equipment for a period of interval to do this work.

The data on power generation plants were obtained from each power station during 2013-2014. We had obtained only 24-month monthly dataset during 2013-2014 due to lack of recording of data availability. We selected Sylhet region purposively in Bangladesh for data collection. We collected the recorded data from each power generation plant. In Sylhet division, there are thirteen power generation plants and we had selected five power stations randomly which were Sylhet Gas Turbine Power Station (Sylhet GTPP, $150 \mathrm{MW}$ ), Fenchuganj Combined Cycle Power Plant (Fenchuganj CCPP, $97 \mathrm{MW}$ ), Sylhet Combined Cycle Power Plant (Sylhet CCPP, 150 MW), Shahjibazar Power Station (PS, $330 \mathrm{MW}$ ), and Desh Energy (DE, $10 \mathrm{MW}$ ). Four plants are governmental and one is private power plant among five power generation plants in Sylhet region. The description of power generation plants has been given in Table 1 .

2.1. Gross Electricity Generation (Y). Electricity generation is the process of generating electric power from other sources of primary energy. Gross generation or gross electric output is the total generation of electricity produced by an electric power plant. It is measured at the plant terminal prior to the point at which the power leaves the station and is measured in kilowatt hours $(\mathrm{kWh})$ or megawatt hours (MWh).

\subsubsection{Input Variables for SFA}

(1) Fuel Cost (FC). In electrical power generation, the distinct ways of generating electricity incur significantly different costs. Calculations of these costs at the point of connection to a load or to the electricity grid can be made. The cost is typically given per kilowatt hour or megawatt hour. It includes the initial capital, discount rate, and the costs of continuous operation, fuel, and maintenance.

(2) Fuel Consumption (FCS). Natural gas is the main fuel for power generation plants. Natural gas (also called fossil gas) is a naturally occurring hydrocarbon gas mixture consisting primarily of methane, but commonly including varying amounts of other higher alkanes and sometimes a small percentage of carbon dioxide, nitrogen, hydrogen sulfide, or helium. According to the type of fuel and working fluid, the power plants are classified as steam turbine power plant, gas turbine power plant, coal-fired power plant, or combined cycle power plant, etc. All plants use the energy extracted from expanding gas, either steam or combustion gases. There are also small captive power plant assemblies that are present such as diesel engine plants or gas engine plants. All power plants work on the same principle, driven by the prime mover of the turbine. If the pressurized steam is expanded to the turbine, then it is called a steam turbine plant, and if combustible flue gas is expanded in the turbine, then it is called a gas turbine.
(3) Lube Oil Consumption (LOC). Lube oil or lubricating oil is used to reduce friction and wear, remove heat generated by friction, and prevent corrosion. A perfect lubricant has high viscosity index, thermal stability, hydraulic stability, and high resistance to oxidation. Its basic functions within an engine include reducing friction, cooling, cleaning, and serving as protection for moving parts. So without this lubricating oil, power generation will be interrupted.

(4) Auxiliary Consumption (AC). In power plants, auxiliaries circulate steam-water cycle safely, and it returns thermodynamic starting point. The starting point for most thermodynamic considerations is the laws of thermodynamics, which postulate that energy can be exchanged between physical systems as heat or work. There are a lot of auxiliary systems present to aid proper water to steam conversion and to maintain cycle efficiency. The auxiliary consumption plays a major role in enriching the energy efficiency of the thermal power plant. Coal quality can have a significant impact on auxiliary consumption [16].

The technology or energy management can be applied to reduce auxiliary consumption in thermal power plants. There are a lot of pumps, compressors, valves, and metering stations present in a power plant facility to keep the cycle operational. These auxiliaries are commonly termed as balance of plant. Without these auxiliary systems, the steamwater cycle would suffer either an immediate collapse or a dangerous and nonsustainable expansion.

Auxiliary consumption of thermal power plant is between 8 and $10 \%$ of the total power produced. For instance, for thermal power plant having $10 \mathrm{MW}$ capacity, auxiliary consumption is around 850 to $1000 \mathrm{~kW}$.

(5) Heat Rate (HR). Heat rate measures the efficiency of electrical generators/power plants that convert a fuel into heat and into electricity for per unit generation. The heat rate is the amount of energy used by an electrical generator/ power plant to generate one kilowatt hour (kWh) of electricity. According to the US Energy Information Administration, the Bangladesh Power Development Board also expresses heat rates in British thermal units (Btu) per net $\mathrm{kWh}$ generated. The heat rate measures the combined performance of the gas turbine cycle, the steam turbine cycle, and any other associated auxiliaries.

(6) Hours Run (HOR). Hours run or hours work in a power generation plant means how much time it works in a day or a month or in a year. If all instruments run so good, then power plants can work maximum hours and give a maximum output of power generation. Table 2 describes the data for this study.

\section{Methodology}

3.1. Stochastic Frontier Model. To estimate the efficiency of power generation, a transcendental logarithmic functional form is selected. This study uses the trans-log stochastic frontier model developed by Aigner et al. [17]. Later, Meeusen and Van den Broeck [18] have developed the 
TABLE 1: Description of power generation plants.

\begin{tabular}{|c|c|c|c|}
\hline Power plant station & Gross power generation & Activity & Types of fuel \\
\hline Sylhet Gas Turbine Power Station & $150 \mathrm{MW}(1 \times 150)$ & Since 2012 & Natural gas \\
\hline Fenchuganj Combined Cycle Power Plant & $90 \mathrm{MW}(1 \times 90)$ & Since 2016 & Gas \\
\hline Sylhet Combined Cycle Power Plant & $90 \mathrm{MW}(1 \times 150)$ & Since 1995 & Natural gas \\
\hline Shahjibazar Power Station & $330 \mathrm{MW}(1 \times 330)$ & Since 2009 & Natural gas \\
\hline $\begin{array}{l}\text { Desh Energy Limited/Desh Cambridge } \\
\text { Kumargaon Power Company Limited }\end{array}$ & $11.70 \mathrm{MW}(1 \times 11.70)$ & Since 2005 & $\begin{array}{c}\text { Gas as its primary fuel through a } 15 \text {-year gas } \\
\text { supply agreements with JalalabadGas Transmission } \\
\text { and Distribution Company }\end{array}$ \\
\hline
\end{tabular}

Owner: Bangladesh Power Development Board (BPDB). Shareholders: Government of Bangladesh (GoB).

TABle 2: Descriptive statistics.

\begin{tabular}{lccc}
\hline Description of variables & Notation & Mean & Standard deviation (STD) \\
\hline Gross generation $(\mathrm{kWh})$ & Y & 39066490.89 & 31423506.05 \\
Fuel and other costs (TK) & FC & 33443433.89 & 21534089.12 \\
Fuel consumption $\left(\mathrm{M}^{3}, 1 \mathrm{M}^{3}=35.31 \mathrm{cft}\right)$ & FCS & 11181823.90 & 8408057.816 \\
Lube oil consumption (L) & LOC & 825.90 & 895.8637 \\
Auxiliary consumption (kWh) & AC & 537555.90 & 614019.81 \\
Heat rate (Btu/kWh) & HR & 21245.37 & 17451.29 \\
Hours run (monthly) & HOR & 599.84 & 158.123 \\
\hline
\end{tabular}

stochastic frontier production function to measure the technical efficiency of production. The stochastic frontier production function is more appropriate for measuring efficiency because this production function overcomes the inadequate characteristics of the conventional error term in production functions which have limitations on statistical inference of the parameters.

According to stochastic frontier production function, the estimation of the technical efficiency of power plants had been done using stochastic frontier production function model within three phases.

Step 1. :Stochastic frontier production model is estimated using the following model with two composed error terms:

$$
Y_{i t}=\exp \left(X_{i t} \beta+V_{i t}-U_{i t}\right) ; \quad i=1,2, \ldots, n ; t=1,2, \ldots, T \text {. }
$$

where $Y_{i t}$ is the total generation in logarithm form of $i$ th power plants $i=1,2, \ldots, n ; X_{i t}(1 \times T)$ is a matrix of inputs in logarithm form; $\beta_{t}$ is a vector (1X T) of unknown parameters; and $V_{i t}$ are random variables which are assumed to be independently identically distributed, i.e., $N\left(0, \sigma_{v}^{2}\right)$ and $U_{i t}$ are nonnegative random variables which are assumed to be an identically independently distributed $N\left(0, \sigma_{v}^{2}\right)$.

According to Jondrow et al. [19], the relative efficiency of a firm can be estimated by means of the ratio, $\lambda=\left(\sigma_{u} / \sigma_{v}\right)$. If the efficiency factor, which is under the control of management, dominates the random factor, which is beyond the control of management, the $\lambda$ attains large value [20].

The parameters in equation (1) include the variance parameters $\sigma^{2}=\sigma_{v}^{2}+\sigma_{u}^{2}$ and $\gamma=\left(\sigma_{u}^{2} / \sigma^{2}\right)[21]$, where $\sigma^{2}$ is the sum of the error variance and $\gamma$ has a value between zero and one, which measures the total variation of output from the frontier that attributed to the existence of random noise or inefficiency.
Step 2. Time behavior inefficiency effects model.

Battese and Coelli [20] proposed a simple model that can be used to estimate the time behavior inefficiencies followed by Kumbhakar [22], which are assumed to be distributed as truncated normal and half-normal distribution:

$$
u_{i t}=-\eta_{i} u_{i}=u_{i} \exp (-\eta[t-T]), \quad t \in \tau(i),
$$

where $u_{i t}$ is an independently identically distributed nonnegative error term following a truncated normal distribution $N\left(\mu, \sigma_{u}^{2}\right), \eta$ is an unknown scalar parameter to be estimated, which determines whether inefficiencies are timevarying or time-invariant.

This unknown parameter $\eta$ represents the rate of change in technical inefficiency and $u_{i t}$ 's, where $i=1,2, \ldots n$ is the nonnegative random variable, which is the technical inefficiency effect for the $i$ th plants. That is, the technical inefficiency effects in the earlier periods are a deterministic exponential function of the inefficiency effects for the corresponding plants in the final period (i.e., $u_{i t}=u_{i}$, given that the data for the $i$ th industries are available in period $T$ ).

$\tau(i) \in[1,2, \ldots, T]$ is the set of $T$, time periods for which observations for the $i$ th plants are obtained. If $\eta$ is positive, then $-\eta(t-T) \equiv \eta(T-t)$ is positive for $t<T$ and so $\exp [\eta(t-T)]>1$, which implies that the technical inefficiencies of industries decline over time. However, if $\eta$ is negative, then $-\eta(t-T)<0$, and thus, the technical inefficiencies increase over time.

Thus, in the above model, time-varying efficiency is assumed to follow an exponential function of time, involving only one parameter to be estimated. Technical inefficiency either increases at a decreasing rate, when $\eta$ is greater than zero, or decreases at an increasing rate when $\eta$ is less than zero. If $\eta$ is equal to zero, then the time-invariant model is obtained. 
The most important advantage of a stochastic frontier production function is that it enables one to estimate inefficiency which is time-dependent.

Step 3. The technical efficiency of power plant for the $i$ th firm at the th observation is defined as follows:

$$
\mathrm{TE}_{i t}=\exp \left(-U_{i t}\right) \text {. }
$$

These stochastic frontier production model in (1), time-varying inefficiency models in (2), and technical efficiency model in (3) were estimated altogether by using maximum-likelihood estimation through software Frontier 4.1.

3.2. Hypothesis Tests. Hypothesis test for maximum-likelihood method can be written as follows:

$$
\lambda=-2\left\{\ln \left[L\left(H_{0}\right) / L\left(H_{1}\right)\right]\right\}=-2\left\{\ln \left[L\left(H_{0}\right)\right]-\ln \left[L\left(H_{1}\right)\right]\right\},
$$

where $L\left(H_{0}\right)$ and $L\left(H_{1}\right)$ are the values of the likelihood function under the null and alternative hypothesis (note that this statistic has a mixed chi-square distribution). The null hypothesis is rejected when $\lambda_{\mathrm{LR}}>\chi_{c}{ }^{2}$. To test the hypothesis, a tested hypothesis is performed to determine whether the Cobb-Douglas (C-D) specification is an adequate representation of the frontier production function or not. This test uses the log-likelihood ratio test and has been given in Table 3 . The null hypothesis $H_{0}: \beta_{i j}=0$ specifies that $\mathrm{C}-\mathrm{D}$ stochastic frontier model is more preferable than trans-log stochastic frontier model. From the result, it is observed that the null hypothesis is rejected so the trans-log model is more preferable than the C-D. The null hypothesis $H_{0}: \gamma=0$, which specifies no technical inefficiency effects, is strongly rejected for all power plants. This shows that trans-log production function is not equivalent to the traditional average response function. Then, the frontier model could not be reduced to a mean response production function (OLS estimation) to represent the data precisely. Given the specification of the stochastic frontier with time-varying inefficiency effects, the null hypotheses $H_{0}: \eta=0$ and $H_{0}: \mu=0$, which also explore that the technical inefficiency effects are time-invariant and half-normal distribution, are rejected, indicating that technical inefficiency effect varies significantly over time and that truncated normal distribution is preferable to the halfnormal distribution for inefficiency effect.

\section{Results and Discussions}

The results of time-invariant maximum-likelihood estimation (MLE) of the trans-log production frontier model assuming a half-normal and truncated normal distribution for the electricity supply plant in Bangladesh are presented in Table 4. The coefficient of fuel cost is highly statistically significant for both half-normal distribution and truncated normal distribution. The parameter estimates for fuel are highly significant for both half-normal and truncated
TABLE 3: Likelihood ratio test.

\begin{tabular}{lcccc}
\hline $\begin{array}{l}\text { Null } \\
\text { hypothesis }\end{array}$ & $\begin{array}{c}\text { Log- } \\
\text { likelihood }\end{array}$ & $\begin{array}{c}\text { Test } \\
\text { statistic }\end{array}$ & $\begin{array}{c}\text { Critical } \\
\text { value }\end{array}$ & Decision \\
\hline$H_{0}: \beta_{i j}=0$ & -75.49 & 93.65 & 5.14 & Reject $H_{0}$ \\
$H_{0}: \gamma=0$ & -92.54 & 78.32 & 38.30 & Reject $H_{0}$ \\
$H_{0}: \mu=0$ & -67.23 & 10.78 & 3.84 & Reject $H_{0}$ \\
$H_{0}: \eta=0$ & -61.76 & 7.09 & 3.84 & Reject $H_{0}$ \\
\hline
\end{tabular}

Notes: all critical values are at the $5 \%$ level of significance. The critical values are obtained from table of Kodde and Palm (1986).

normal distribution. Another two input variables are lube oil consumption and heat rate and lube oil consumption is statistically significant at $10 \%$ for half-normal distribution and heat rate is significant at $1 \%$ level for truncated normal distribution. Other input variables are insignificant for both normal distribution and truncated normal distribution. Therefore, we conclude that fuel is more positively correlated with input than the other inputs in the production process for power generation plant.

The interaction between fuel consumption and lube oil consumption is highly significant at the $1 \%$ level. Fuel and lube oil are the two most essential elements of the electricity supply industry. The coefficient of interaction between auxiliary consumption and heat rate is negative, but significant at the 5\% level of significance for half-normal distribution. Again, the parameter of the coefficient of the square of fuel cost is significant at the $1 \%$ level for truncated normal. Interaction between lube oil consumption and heat rate is significant for truncated normal distribution. All other squares of the input variables and interaction between them are insignificant for half-normal and truncated normal distribution.

The results of MLE of the trans-log production frontier model assuming a half-normal distribution and truncated normal distribution with time-varying inefficiency effects model for power generation plants are given in Table 5. The value of coefficient for half-normal and truncated normal of fuel cost is 0.294 and 0.275 , respectively, which is significant at the $5 \%$ level of significance.

Therefore, cost is an important factor for the power generation plant or the electricity supply industry. The coefficient of fuel is significant for half-normal distribution, but it is insignificant for truncated normal distribution. The parameter of the coefficient hours' runs is negative but significant for half-normal distribution. The coefficient of lube oil consumption is significant for truncated normal, but square of this coefficient is highly significant. The interaction between fuel consumption and lube oil consumption is highly significant at the $1 \%$ level of significance for half-normal and truncated normal distribution. Therefore, it has been showed that fuel and lube oil are the two most important elements of the electricity supply industry.

The coefficient of the interaction between total cost and heat rate for half-normal and truncated normal distribution is negative but significant at the $1 \%$ level. The interaction between auxiliary consumption and hours run is significant for half-normal distribution. Again, the coefficient of the 
TABLE 4: Maximum-likelihood estimation with time-invariant inefficiency model.

\begin{tabular}{|c|c|c|c|c|}
\hline \multirow[t]{2}{*}{ Variable } & \multicolumn{2}{|c|}{$\begin{array}{c}\text { Truncated } \\
\text { distribution } \\
\text { (time-invariant) }\end{array}$} & \multicolumn{2}{|c|}{$\begin{array}{c}\text { Half-normal } \\
\text { distribution } \\
\text { (time-invariant) }\end{array}$} \\
\hline & Coefficient & STD & Coefficient & STD \\
\hline Constant & $-0.916^{\mathrm{a}}$ & 0.987 & $0.945^{\mathrm{c}}$ & 0.100 \\
\hline $\mathrm{FC}$ & 0.282 & 0.829 & $0.253^{\mathrm{a}}$ & 0.838 \\
\hline FCS & $0.393^{\mathrm{a}}$ & 0.856 & $0.314^{\mathrm{a}}$ & 0.832 \\
\hline LOC & 0.146 & 0.982 & $0.273^{c}$ & 0.107 \\
\hline $\mathrm{AC}$ & 0.194 & 0.920 & 0.145 & 0.968 \\
\hline HR & $0.340^{\mathrm{a}}$ & 0.928 & 0.280 & 0.999 \\
\hline HOR & 0.899 & 0.978 & 0.521 & 0.998 \\
\hline $\mathrm{FC}^{2}$ & $0.257^{\mathrm{a}}$ & 0.787 & -0.183 & 0.765 \\
\hline $\mathrm{FCS}^{2}$ & -0.121 & 0.826 & -0.146 & 0.739 \\
\hline $\mathrm{LOC}^{2}$ & $0.132^{\mathrm{a}}$ & 0.959 & 0.132 & 0.176 \\
\hline $\mathrm{AC}^{2}$ & 0.854 & 0.895 & 0.801 & 0.531 \\
\hline $\mathrm{HR}^{2}$ & -0.271 & 0.925 & -0.238 & 0.611 \\
\hline $\mathrm{HOR}^{2}$ & $0.389^{c}$ & 0.979 & 0.332 & 0.527 \\
\hline $\mathrm{FC} \times \mathrm{FCS}$ & 0.764 & 0.669 & 0.663 & 0.648 \\
\hline $\mathrm{FC} \times \mathrm{LOC}$ & -0.139 & 0.775 & 0.123 & 0.498 \\
\hline $\mathrm{FC} \times \mathrm{AC}$ & $-0.440^{\mathrm{a}}$ & 0.719 & -0.640 & 0.440 \\
\hline $\mathrm{FC} \times \mathrm{HR}$ & 0.663 & 0.756 & -0.704 & 0.574 \\
\hline $\mathrm{FC} \times \mathrm{HOR}$ & -0.219 & 0.790 & -0.294 & 0.744 \\
\hline $\mathrm{FCS} \times \mathrm{LOC}$ & $0.348^{\mathrm{a}}$ & 0.818 & $0.357^{\mathrm{a}}$ & 0.590 \\
\hline $\mathrm{FCS} \times \mathrm{AC}$ & -0.988 & 0.746 & 0.975 & 0.433 \\
\hline $\mathrm{FCS} \times \mathrm{HR}$ & 0.170 & 0.774 & 0.273 & 0.603 \\
\hline $\mathrm{FCS} \times \mathrm{HOR}$ & -0.350 & 0.815 & -0.359 & 0.808 \\
\hline $\mathrm{LOC} \times \mathrm{AC}$ & 0.810 & 0.849 & 0.876 & 0.211 \\
\hline $\mathrm{LOC} \times \mathrm{HR}$ & $0.619^{\mathrm{b}}$ & 0.918 & 0.723 & 0.272 \\
\hline $\mathrm{LOC} \times \mathrm{HOR}$ & 0.145 & 0.947 & 0.149 & 0.357 \\
\hline $\mathrm{AC} \times \mathrm{HR}$ & 0.700 & 0.838 & $-0.639^{\mathrm{b}}$ & 0.282 \\
\hline $\mathrm{AC} \times \mathrm{HOR}$ & 0.376 & 0.870 & 0.380 & 0.582 \\
\hline $\mathrm{HR} \times \mathrm{HOR}$ & 0.342 & 0.900 & 0.417 & 0.418 \\
\hline Sigma & $0.837^{\mathrm{a}}$ & 0.056 & $0.083^{\mathrm{a}}$ & 0.011 \\
\hline Gamma & $0.510^{\mathrm{a}}$ & 0.837 & $0.092^{\mathrm{a}}$ & 0.020 \\
\hline $\mathrm{Mu}$ & $-0.183^{\mathrm{a}}$ & 0.342 & 0 & 0 \\
\hline Eta & 0 & 0.578 & 0 & 0 \\
\hline Log-likelihood & \multicolumn{2}{|c|}{71.584} & \multicolumn{2}{|c|}{84.638} \\
\hline Mean efficiency & \multicolumn{2}{|c|}{0.930} & \multicolumn{2}{|c|}{0.905} \\
\hline
\end{tabular}

${ }^{\mathrm{a}}$ Significance at the $1 \%$ level; ${ }^{\mathrm{b}}$ significance at the $5 \%$ level; ${ }^{\mathrm{c}}$ significance at the $10 \%$ level.

interaction between auxiliary consumption and heat rate is significant for truncated normal distribution. All other squares of input variables and interaction between them are insignificant for half-normal and truncated normal distribution of the trans-log production model.

Mugabe et al. [23] showed that state-level elasticity of substitution between natural gas and coal has a positive effect on technical efficiency and a negative effect on $\mathrm{CO}_{2}$ emissions using state-level data. See and Coelli [24] showed ownership, plant size, and fuel type have a significant influence on technical efficiency levels. They also showed gasfired power plants tend to be more technically efficient than other power plants. They showed plant age has no statistically significant influence on the technical efficiencies of Malaysian thermal power plants. The analysis of energy efficiency can yield significant insights into the performance of energy units and their potential for increasing productivity and improving resource use [24].
4.1. Technical Efficiency. Technical efficiency (TE) can be defined as minimum sets of input required to produce a given level of output under certain production technology. Efficiency values range from 0 to 1 . Plant efficiencies range from 0 to 1 whereas 0 means nonefficient plant and 1 means efficient plant. A plant is technically efficient if it uses the minimal level of inputs or the input mix to produce the maximal level of output [25]. Our one hypothesis was "the model is time-invariant over time-variant model". The hypothesis was rejected that is why we have added timevarying model efficiencies only in the results. Plant-specific mean technical efficiencies according to half-normal and truncated normal distribution model estimated over the reference periods are presented in Figures 1(a) and 1(b), respectively.

For the half-normal distribution, there is a very small variation in the technical efficiencies among the different power generation plants, and it ranges from a low efficiency from 0.784 to a high efficiency of 0.975 in Figure 1(a) for Sylhet CCPP and Fenchuganj CCPP plants, respectively. This result suggests that there is potentiality for increasing power generation in Sylhet of Bangladesh through existing technology.

Meanwhile, the same scenarios exist for truncated normal distribution, and the efficiency ranges from 0.786 to 0.979 in Figure 1(b) for Sylhet CCPP and Fenchuganj CCPP plants, respectively.

Among all other power plants, the technical efficiency of Sylhet CCPP is 0.784 which is little bit less than others. It happened because producers or the plants could not utilize their input variables in a significant manner. Producers can also improve their power generation using their set of input bundles as other power plants. About our results, we can say that the power plant Sylhet CCPP had that opportunity to produce the maximum level of output like others using the best combination of input. The concept of efficiency works based on using minimal set of input to produce maximum set of output.

The value of gamma coefficient is 0.469 and 0.210 for truncated and half-normal distribution, respectively, and both are significant at the $1 \%$ level of significance (Table 5). This shows that the output variations among the power plants are dominated by technical inefficiency rather than random shocks. The predicted technical efficiencies of all plants range from 0.784 to 0.975 for half-normal and 0.786 to 0.979 for the truncated distributed production model. The overall mean technical efficiency was 0.9271 and 0.9027 for time-varying truncated and half-normally distributed production model, respectively (Table 5). That means the mean technical efficiencies for the plants are found to be $92.70 \%$ for truncated normally distributed production model. This result shows that plants can produce about $92.70 \%$ and 90.28\% maximum attainable outputs using sets of input for the truncated and half-normally distributed production model. These results indicate that if those plants use their existing level of inputs in an efficient manner, output on average can be increased by $10 \%$ or $8 \%$, respectively.

Figures 2(a) and 2(b) show monthwise average technical efficiency followed by time-varying half-normal and 
TABLE 5: Maximum-likelihood estimation with time-variant inefficiency model.

\begin{tabular}{|c|c|c|c|c|}
\hline \multirow{2}{*}{ Variable } & \multicolumn{2}{|c|}{ Truncated distribution (time-varying) } & \multicolumn{2}{|c|}{ Half-normal distribution (time-varying) } \\
\hline & Coefficient & Standard error & Coefficient & Standard error \\
\hline Constant & $-0.892^{\mathrm{a}}$ & 0.987 & $0.912^{\mathrm{a}}$ & 0.100 \\
\hline FC & $0.275^{\mathrm{b}}$ & 0.829 & $0.294^{\mathrm{b}}$ & 0.158 \\
\hline FCS & 0.287 & 0.856 & $0.389^{\mathrm{b}}$ & 0.188 \\
\hline LOC & $0.152^{\mathrm{b}}$ & 0.982 & 0.137 & 0.176 \\
\hline $\mathrm{AC}$ & 0.209 & 0.920 & 0.188 & 0.333 \\
\hline HR & 0.349 & 0.928 & 0.329 & 0.665 \\
\hline HOR & 0.775 & 0.978 & $-0.378^{\mathrm{a}}$ & 0.804 \\
\hline $\mathrm{FC}^{2}$ & -0.359 & 0.787 & 0.335 & 0.610 \\
\hline $\mathrm{FCS}^{2}$ & -0.224 & 0.826 & -0.112 & 0.463 \\
\hline $\mathrm{LOC}^{2}$ & 0.139 & 0.959 & $0.151^{\mathrm{a}}$ & 0.223 \\
\hline $\mathrm{AC}^{2}$ & 0.861 & 0.895 & 0.924 & 0.633 \\
\hline $\mathrm{HR}^{2}$ & -0.236 & 0.925 & -0.255 & 0.183 \\
\hline $\mathrm{HOR}^{2}$ & 0.337 & 0.979 & 0.608 & 0.646 \\
\hline $\mathrm{FC} \times \mathrm{FCS}$ & $0.825^{\mathrm{a}}$ & 0.669 & 0.790 & 0.349 \\
\hline $\mathrm{FC} \times \mathrm{LOC}$ & -0.237 & 0.775 & -0.123 & 0.145 \\
\hline $\mathrm{FC} \times \mathrm{AC}$ & -0.470 & 0.719 & -0.422 & 0.127 \\
\hline $\mathrm{FC} \times \mathrm{HR}$ & $-0.646^{\mathrm{a}}$ & 0.756 & $-0.655^{\mathrm{a}}$ & 0.358 \\
\hline $\mathrm{FC} \times \mathrm{HOR}$ & -0.314 & 0.790 & -0.187 & 0.414 \\
\hline $\mathrm{FCS} \times \mathrm{LOC}$ & $0.719^{\mathrm{b}}$ & 0.818 & $0.480^{\mathrm{a}}$ & 0.150 \\
\hline $\mathrm{FCS} \times \mathrm{AC}$ & -0.489 & 0.746 & -0.119 & 0.109 \\
\hline $\mathrm{FCS} \times \mathrm{HR}$ & 0.574 & 0.774 & 0.163 & 0.385 \\
\hline $\mathrm{FCS} \times \mathrm{HOR}$ & -0.393 & 0.815 & -0.387 & 0.434 \\
\hline $\mathrm{LOC} \times \mathrm{AC}$ & 0.814 & 0.849 & 0.783 & 0.262 \\
\hline $\mathrm{LOC} \times \mathrm{HR}$ & 0.374 & 0.918 & 0.583 & 0.381 \\
\hline $\mathrm{LOC} \times \mathrm{HOR}$ & 0.149 & 0.947 & 0.148 & 0.496 \\
\hline $\mathrm{AC} \times \mathrm{HR}$ & $0.742^{\mathrm{b}}$ & 0.838 & 0.737 & 0.310 \\
\hline $\mathrm{AC} \times \mathrm{HOR}$ & 0.325 & 0.870 & $0.386^{\mathrm{b}}$ & 0.945 \\
\hline $\mathrm{HR} \times \mathrm{HOR}$ & 0.359 & 0.900 & 0.350 & 0.147 \\
\hline Sigma & 0.772 & 0.056 & 0.108 & 0.049 \\
\hline Gamma & $0.469^{\mathrm{a}}$ & 0.837 & $0.210^{\mathrm{a}}$ & 0.313 \\
\hline $\mathrm{Mu}$ & $0.398^{\mathrm{c}}$ & 0.342 & 0 & 0 \\
\hline Eta & $0.030^{\mathrm{a}}$ & 0.578 & $0.300^{\mathrm{a}}$ & 0.214 \\
\hline Log-likelihood & & & & \\
\hline Mean efficiency & & & & \\
\hline
\end{tabular}

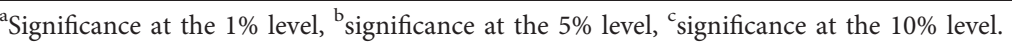

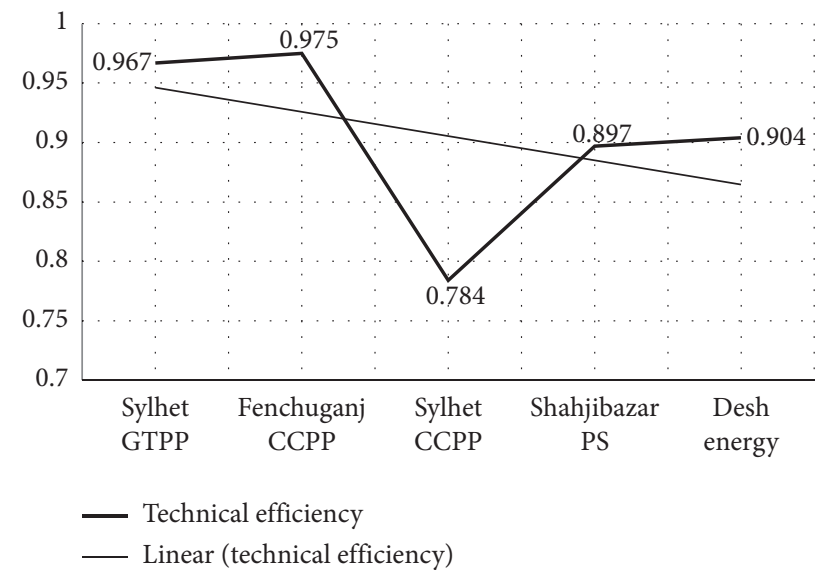

(a)

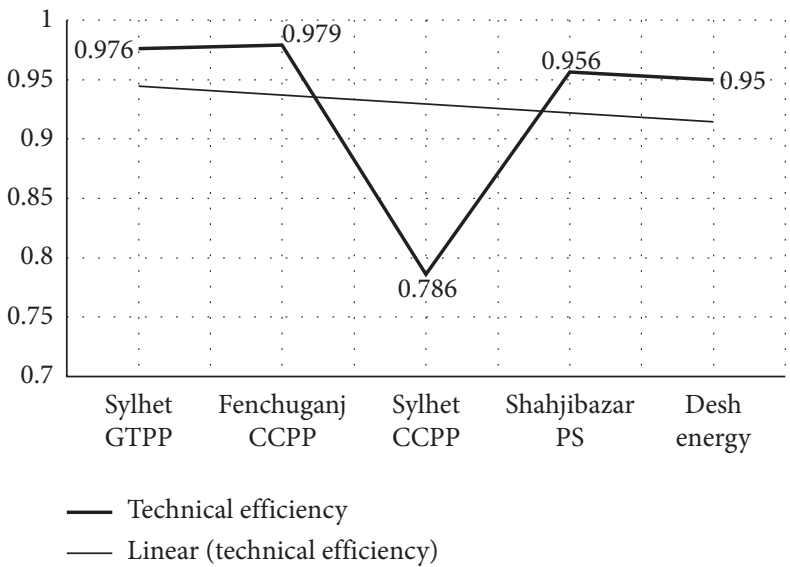

(b)

FIGURE 1: (a) Plantwise mean efficiency of time-varying half-normal stochastic frontier model. (b) Plantwise mean efficiency of time-varying truncated normal stochastic frontier model. 


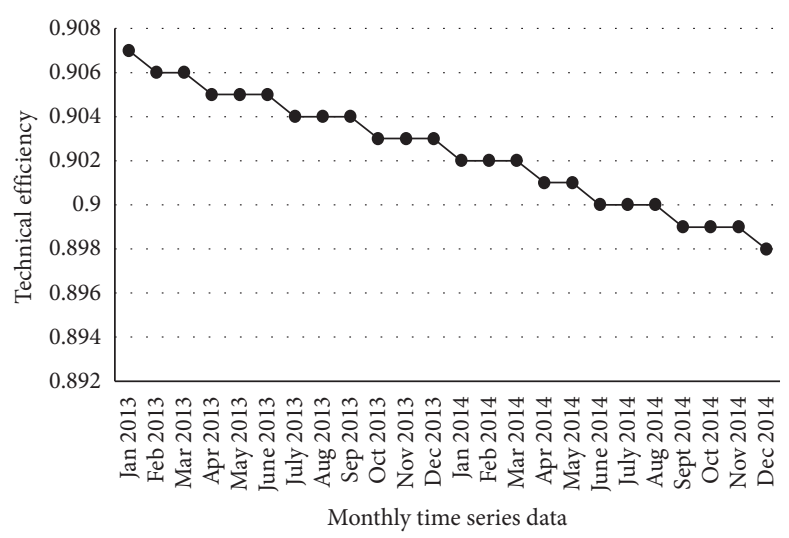

(a)

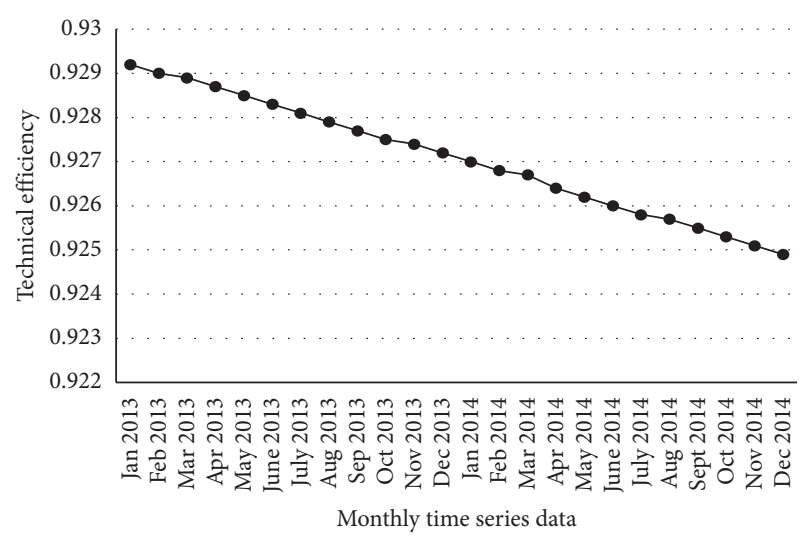

(b)

FIGURE 2: (a) Monthwise technical efficiency of half-normally distributed stochastic frontier model. (b) Monthwise technical efficiency of truncated normally distributed stochastic frontier model.

truncated normally distributed production model for 24month dataset in the years 2013-2014, respectively. It has been shown that the monthwise efficiency was decreasing from January 2013 to December 2014 in case of both production models.

The monthwise mean technical efficiency of the power generation plants in Sylhet region of Bangladesh during the periods 2013-2014 for the half-normally distributed production model is found to be $90.28 \%$ which is presented in Table 5. This implies that 90.28 percent of potential output is being realized by the power generation plants in Sylhet region of Bangladesh according to the half-normal distribution model. This value indicates that plants can improve their output level by 9.72 (i.e., 1-90.28) percent by the same set of given inputs and technology.

In the $1^{\text {st }}$ month of 2013 , the mean efficiency was $90.70 \%$ whereas the mean efficiency was $90.27 \%$ in the $1^{\text {st }}$ month of 2014 which was decreasing. According to the other monthly data, the mean efficiency was decreasing. So, the highest mean technically efficient month is January 2013 with the value of $90.70 \%$ and the lowest mean efficient month was December 2014 which was $89.87 \%$.

The average technical efficiency was assumed by truncated normally distributed production model for 24 months in the years 2013-2014. The mean technical efficiency of the power generation plants in Sylhet region of Bangladesh during the periods 2013-2014 of the truncated normal distribution is found to be $92.71 \%$. This implies that 92.71 percent of potential output is being realized by the power generation plants in Sylhet region of Bangladesh according to the truncated normal distribution. This value indicates that plants can improve their output level by 7.29 percent by using the same set of given inputs and technology. In the month of January 2013, the mean efficiency was $92.92 \%$ whereas the mean efficiency was $92.70 \%$ in the month of January 2014 which was decreasing by $0.22 \%$ in one year. According to the other monthly data, the mean efficiency was decreasing. So, the lowest mean technical efficiency was 92.49 in December 2014 and the higher mean technical efficiency was 92.92 percent in January 2013. Ghosh and kathuria [26] showed the mean technical efficiency of thermal power plants was $76.7 \%$ which indicates there is wide scope for efficiency improvement for power plants in India. The limitation of this study is that this study is based on Sylhet region that is why we could not get the whole scenario of the country. Bangladesh has much room or opportunity to improve power generation in the power sector of the country.

\section{Conclusion}

We have analyzed the trans-log stochastic frontier production model with two distributional assumptions, and we observed that the estimated values of the time-varying inefficiency parameter $\eta$ are positive for both the truncated and the half-normal distribution. These results indicate that the technical efficiency has declined over the reference period. Tests for different null hypotheses showed that the presence of one-sided error component was justified by the LR test individually, which was recorded significant for these models. We found that the trans-log stochastic frontier production model is more preferable than the C-D stochastic frontier production model. The variation in the observed level of output is not just due to random shocks but also can be explained by the differences in the levels of technical efficiency in the power plants. The truncated (at zero) normal distribution is preferable to the half-normal distribution for the technical inefficiency effects. The technical inefficiency effect varies significantly over time. It is observed that the monthwise and plantwise truncated normal distribution gives higher mean technical efficiency estimates than the half-normal distribution. From the results of the study, it is highly recommended to monitor power distribution companies to excel their efficiency and combat the sufferings for mass people. With regard to plant operation and maintenance, there is a need for the BPDB to make further improvements to the technical level of its employees by providing training and so forth. In addition, restructuring is currently underway at BPDB in line with government reforms of the power sector, and thus, careful monitoring of 
the situation is necessary. The study covered only one district in Bangladesh. Similar studies in different geographical locations in Bangladesh would provide more detail and comprehensive information on the level of technical efficiency in power generation plants in Bangladesh.

\section{Data Availability}

The data used to support the findings of this study are available from the corresponding author upon request.

\section{Conflicts of Interest}

All authors declare that they have no conflicts of interest.

\section{References}

[1] The Economist Intelligence Unit (EIU), Bangladesh: Country Profile, The Economist Intelligence Unit (EIU), London, UK, 2005.

[2] S. K. N. Uddin and R. Taplin, "A sustainable energy future in Bangladesh: current situation and need for effective strategies," in Proceedings of the The 2nd Joint International Conference on Sustainable Energy and Environment, Bangkok, Thailand, 2006

[3] Energy Information Administration, Bangladesh: Country Analysis Briefs, Energy Information Administration, Washington, DC, USA, 2005.

[4] Japan International Cooperation Agency (JICA), Bangladesh Power System Master Plan PSMP, Tokyo Electric Power Co., Ltd, Tokyo, Japan, 2010.

[5] M.-J. Li and W.-Q. Tao, "Review of methodologies and polices for evaluation of energy efficiency in high energy-consuming industry," Applied Energy, vol. 187, pp. 203-215, 2017.

[6] J.-P. Liu, Q.-R. Yang, and L. He, "Total-factor energy efficiency (TFEE) evaluation on thermal power industry with DEA, malmquist and multiple regression techniques," Energies, vol. 10, no. 7, p. 1039, 2017.

[7] Rashid and Sajjad, Powering the Nation, Dhaka Tribune, Nuclear Power in Bangladesh, Ruppur, Bangladesh, 2018, https://world-nuclear.org.

[8] A. Hassan, M. S. Rahman, F. T. Khan, M. B. Malik, and M. Z. Ali, "Electricity challenge for sustainable future in Bangladesh,” APCBEE Procedia, vol. 1, pp. 346-350, 2012.

[9] S. Islam and M. Z. R. Khan, "A review of energy sector of Bangladesh," Energy Procedia, vol. 110, pp. 611-618, 2017.

[10] H. Geller, P. Harrington, A. H. Rosenfeld, S. Tanishima, and F. Unander, "Polices for increasing energy efficiency: thirty years of experience in OECD countries," Energy Policy, vol. 34, no. 5, pp. 556-573, 2006.

[11] M. J. Farrell, "The measurement of productive efficiency," Journal of the Royal Statistical Society. Series A (General), vol. 120, no. 3, pp. 253-290, 1957.

[12] B. Lin and H. Long, "A stochastic frontier analysis of energy efficiency of China's Chemical Industry," Journal of Cleaner Production, vol. 87, pp. 235-244, 2015.

[13] A. Mardani, E. K. Zavadskas, D. Streimikiene, A. Jusoh, and M. khoshnoudi, "A comprehensive review of DATA envelopment analysis (DEA) approach in energy efficiency," Renewable and Sustainable Energy Reviews, vol. 70, pp. 1298-1322, 2017.

[14] A. Otsuka, Determinants of Energy Efficiency: Stochastic Frontier Analysis. Regional Energy Demand and Energy
Efficiency in Japan: An Application of Economic Analysis, Springer International Publishing, Cham, Switzerland, 2017.

[15] T. Sueyoshi, Y. Yuan, and M. Goto, "A literature study for DEA applied to energy and environment," Energy Economics, vol. 62, pp. 104-124, 2017.

[16] B. Miller, "Fuel considerations and burner design for ultrasupercritical power plants," in Ultra-Supercritical Coal Power Plants Materials, Technologies and Optimisation, pp. 57-80, Woodhead Publishing Series in Energy, Cambridge, UK, 2013.

[17] D. Aigner, C. A. K. Lovell, and P. Schmidt, "Formulation and estimation of stochastic frontier production function models," Journal of Econometrics, vol. 6, no. 1, pp. 21-37, 1977.

[18] W. Meeusen and V. van den Broeck, "Technical efficiency and dimension of the firm: some results on the use of frontier production functions," Empirical Economics, vol. 2, no. 2, pp. 109-122, 1977.

[19] J. Jondrow, C. A. Knox Lovell, I. S. Materov, and P. Schmidt, "On the estimation of technical inefficiency in the stochastic frontier production function model," Journal of Econometrics, vol. 19, no. 2-3, pp. 233-238, 1982.

[20] G. E. Battese and T. J. Coelli, "Frontier production functions, technical efficiency and panel data: with application to paddy farmers in India," Journal of Productivity Analysis, vol. 3, no. 1-2, pp. 153-169, 1992.

[21] G. E. Battese and G. S. Corra, "Estimation of a production frontier model: with application to the pastoral zone of eastern Australia," Australian Journal of Agricultural Economics, vol. 21, no. 3, pp. 169-179, 1977.

[22] S. C. Kumbhakar, "Production frontiers, panel data, and timevarying technical inefficiency," Journal of Econometrics, vol. 46 , no. 1-2, pp. 201-211, 1990.

[23] D. Mugabe, L. Elbakidze, and G. Zaynutdinova, "Elasticity of substitution and technical efficiency: evidence from the US electricity generation," Applied Economics, vol. 52, no. 16, pp. 1789-1805, 2020.

[24] K. F. See and T. Coelli, "An analysis of factors that influence the technical efficiency of Malaysian thermal power plants," Energy Economics, vol. 34, no. 3, pp. 677-685, 2012.

[25] C. Cornwell and P. Schmidt, Stochastic Frontier Analysis and Efficiency Estimation, Springer, Berlin, Germany, 2008.

[26] R. Ghosh and V. Kathuria, "The effect of regulatory governance on efficiency of thermal power generation in India: a stochastic frontier analysis," Energy Policy, vol. 89, pp. 11-24, 2016. 